\title{
Narrativa como gesto bibliográfico: Gabriel Naudé entre erudição e política
}

\section{Giulia Crippa}

\begin{abstract}
Livre Docente em Ciência da Informação pela Universidade de São Paulo. Professora associada da Faculdade de Filosofia, Ciências e Letras de Ribeirão Preto da Universidade Federal de São Paulo (USP)
\end{abstract}

http://dx.doi.org/10.1590/1981-5344/3231

O artigo propõe a contextualização de Gabriel Naudé como bibliotecário e pensador em um tempo, o século do desenvolvimento absolutista na França, e em um ambiente, $o$ da libertinagem erudita francesa e das bibliotecas em fase de modernização. Consideramos que uma revisão dentro da condição sócio histórica das atividades de Naudé como bibliotecário e intelectual podem auxiliar em uma maior compreensão de sua produção bibliográfica. Para tanto, realizamos uma releitura historicamente contextualizada do tratado Advis pour dresser une bibliothèque, de 1627 e de sua Bibliographie Politique, obra de 1633, caracterizada por inaugurar o termo bibliografia e, ao mesmo tempo, por representar uma tipologia específica de bibliografia, a chamada história literária. O percurso considerou a leitura das fontes como ponto de partida para o entendimento dos textos, apoiada na literatura crítica.

Palavras-chave: Gabriel Naudé. Advis pour dresser une bibliothèque. Bibliographie Politique. Bibliografia. Biblioteca.

\section{Narrative as a bibliographic gesture: Gabriel Naudé between erudition and politic.}

The article proposes the contextualization of Gabriel Naudé as a librarian and thinker in his time, the century of absolutist development in France, and in an environment, that of French scholarly libertinism and libraries in the process of modernization. We consider that 
a contextualization of the activities of Naudé as a librarian and intellectual can help in a greater understanding of his bibliographic production. To achieve this, we have developed a brief analysis of the treaty Advis pour dresser une bibliothèque (1627), ando $f$ his Bibliographia Politica (1633), characterized by the inauguration of the term bibliography and, at the same time, because it represents a specific typology of bibliography, the so-called literary history. Our path considered the reading of the sources as a starting point for the understanding of the texts, supported by a review of the bibliography.

Keywords: Gabriel Naudé. Advis pour dresser une bibliothèque. Bibliographie Politique. Bibliography. Library.

Recebido em 31.05.2017 Aceito em 30.06.2017

\section{Introdução}

Nesse artigo propomos uma discussão sobre Gabriel Naudé e sua obra como bibliotecário e erudito libertino na França do século XVII, com particular atenção para uma ampliação no âmbito dos estudos históricos sobre bibliotecas a partir da atuação dele. O interesse que os estudos biblioteconômicos reservam a Naudé, porém, é frequentemente restrito ao Advis pour dresser une bibliothèque (NAUDÉ, 1994), pequeno livro que ele dedicou, em 1627, ao presidente do parlamente francês, Henri II de Mesme, para quem Naudé trabalhara em 1625.

Esse libelo constitui um exemplo de escrita biblioteconômico-política de uma época em que as bibliotecas estavam atravessando uma fase de renovação tanto em relação à quantidade de materiais, bem como pelos conteúdos, graças às mudanças que se encontram na esfera dos conhecimentos: novos interesses e descobertas científicas, uma relação geográfico-espacial que se consolida em relação aos novos espaços de conquista europeia, a configuração política dos Estados Absolutistas em via de configuração, mudanças e conflitos em campo religioso desenham novas reflexões sobre as necessidades dos lugares em que os registros vêm se acumulando e organizando, as bibliotecas modernas.

Nesse sentido, Naudé é um pensador que há de ser considerado de maneira ampla dentro de seu contexto histórico e político, para entendermos de maneira mais exaustiva o peso de suas reflexões a respeito da biblioteca que ele deseja constituir. Observando que, ainda hoje, existem alguns limites dentro dos estudos biblioteconômicos, sobre Naudé, propomos aqui um percurso que busque ilustrar e discutir, social, histórica e politicamente, o autor e sua obra.

Em um primeiro momento, procuraremos oferecer algumas pinceladas sobre o contexto em que Naudé vive e atua. Seguiremos, a 
partir daí, esboçando uma biografia do autor, destacando alguns lugares e personalidades com que Naudé entrelaçou seus caminhos. Observaremos os interesses de Naudé enquanto erudito no âmbito de uma época em que está se buscando desenhar o conhecimento científico racional em contraposição às antigas superstições, desenhando o perfil libertário e libertino do autor através de suas obras principais. Finalmente, destacaremos alguns aspectos da obra bibliográfica de Gabriel Naudé a partir de seu pequeno tratado Bibliographia Política (NAUDÉ, 1997), publicado em Veneza em 1633, e a estreita relação do Advis com o pensamento político que norteia sua obra inteira.

\section{Sobre a Bibliographia Política}

A Bibliographia Política é uma obra centrada na proposta de reorganização de livros voltados para o tema da política. Na época em que foi produzida observa-se uma ampliação na produção desse gênero, como se vê pela leitura do próprio tratado, e Naudé apresenta ao leitor uma ampla oferta crítica como repertório desse tema com a finalidade de auxiliar na formação de um juízo crítico os leitores eruditos da época. Não se trata, portanto, de um manual prático, mas de um texto que alimenta a constituição de um gênero específico, o da bibliografia do campo da política: um mapa que, com base nos princípios que norteiam a libertinagem erudita da época, permite traçar caminhos de conhecimento.

$O$ interesse e a atenção que alguns autores revelam para a organização dos saberes e da cultura é, provavelmente, um dos aspectos que melhor revelam a sensibilidade deles em relação às mudanças e às novidades que se afirmam no século XVII século. É uma atitude que atesta, entre outras coisas, como esses intelectuais agem em âmbitos próximos da corte ou do poder político, fato que os torna sensíveis aos novos problemas de uma geral reorganização dos aparatos políticos aos quais em muitos sentidos não é alheia a vida cultural que encontramos na França por volta da metade do século XVII, com Mazarino e Luis XIV.

As funções que tais autores desempenham são, nesse sentido, emblemáticas, como no caso de Naudé que se encontra desenvolvendo as tarefas de bibliotecário às ordens de de Mesmes, do Cardeal Gianfrancesco Guidi de Bagno e do Cardeal Mazarino. Todas essas atividades como bibliotecários, preceptores ou funcionários, provavelmente solicitavam nesses autores uma reflexão sobre aquela tradição histórica e cultural na qual se encontravam operando, na tentativa de realizar uma organização disciplinar práticas de circulação desses saberes selecionados e organizados.

Dentro dessa atitude de parte dos intelectuais 'libertinos' como organizadores de saberes e de conhecimentos, percebe-se, entre outros, o interesse pelo problema das bibliotecas. O tema do uso e do aproveitamento do objeto livro, cada vez mais presente e disponível, colocava, de fato, a questão da organização dos materiais e, ao mesmo tempo, a das possibilidades de informar e atualizar um público - de nobres 
ou príncipes, em primeiro lugar - das novidades editoriais e de como escolher entre elas.

A organização tradicional do saber e a atenção pelas novidades dos debates culturais e científicos se tornam uma questão prioritária com a qual se confrontam não somente pensadores que, como Naudé, são bibliotecários por profissão, mas também autores que são preceptores, funcionários nas instituições ou nos lugares de difusão da cultura oficial, como por exemplo nas academias.

Um interesse claro pelas bibliotecas e sua organização e ordem dos livros em distintos âmbitos disciplinares se encontra, assim, em Gabriel Naudé, típico representante do libertinage érudit.

\section{Naudé e seu contexto}

O interesse pela "arte" do governo já está presente no Renascimento, com autores quais Maquiavél e Guicciardini na Itália e, pouco depois, Jean Bodin, entre os mais relevantes. Gerenciar o Estado é considerada, cada vez mais, uma atividade para a qual príncipes e ministros devem ser preparados e, para tanto, assiste-se ao incremento de uma produção de manuais. No século XVI os manuais são escritos para os príncipes, mas no século XVII seu alcance se amplia para todos aqueles que, efetivamente, trabalham para o Estado, isso é: os "profissionais" da burocracia, os funcionários, que precisam de orientações e que, por sua vez, se tornam os protetores dos autores que compartilham de suas visões. Mas que visões são essas? Soberania e razão de Estado resumem a bagagem ideológica que se desenvolve na Europa seiscentista, como base do absolutismo como forma de governo, ao longo de uma trajetória que se coloca, idealmente, entre as obras de Jean Bodin e Thomas Hobbes. Para Bodin, ponto de partida da elaboração do Estado absolutista, o rei é a fonte do direito, e sua soberania consiste no poder de fazer e desfazer as leis, enquanto no ponto de elaboração final Hobbes justifica o monopólio do uso legítimo da força por parte do Estado, reconhecendo unicamente ao príncipe a plenitude dos direitos (LAW, 1991).

A literatura política do Renascimento, inaugurada por Maquiavel, centraliza a política na cidade-estado, carecendo ainda, porém, de um lastro necessário para governar entidades maiores. É uma época em que os autores se esforçam para racionalizar a vontade de dominação: o estadista não cede às paixões, mas persegue com lucidez a meta da utilidade pública. O que começa a se delinear nas obras dessa época, que embasa as reflexões do século XVII, é a ideia de Estado, do qual se passa a estudar a lógica interna, e os teóricos tentam fornecer uma identidade a essa entidade ainda pouco definida. O Estado, em seu primeiro momento de estruturação do absolutismo, se encontra na necessidade de formar um conjunto de funcionários militares e civis dependentes do Príncipe, e é essa uma inovação destinada a ter consequências tanto no plano administrativo como social, pois marca o surgimento de um estrato burocrático relativamente autônomo, dependente do príncipe, mas animado por interesses próprios (KAMEN, 1995). Característica dos 
autores políticos do século XVII é a convergência de seus interesses com os do príncipe, que encarna a própria essência do Estado e, nesse sentido, o cardeal Mazarino, para o qual Naudé trabalha ao longo de alguns anos, representa um bom exemplo desses ideais: objetivo dele é reforçar a monarquia, e a figura do estadista deve ser vista como a de quem educa o rei à política.

Dentro dessa realidade precisamos colocar a figura de Gabriel Naudé: nascido em Paris em 1600 de família humilde, ainda assim conseguiu se dedicar aos estudos. O novo século apresentava ao jovem Naudé todas as possibilidades dos conhecimentos em transformação: as controversas descobertas científicas e as reflexões filosóficas a elas ligadas ofereciam as bases para buscar novas ordens nos conhecimentos. $O$ ano de seu nascimento coincide, com efeito, com a condenação de Giordano Bruno, e a data de publicação de sua Bibliografia Política, com a abjura de Galilei de suas descobertas sobre o sistema solar. É um século aparentemente confuso, em que o estudo do cosmos ainda se confunde com as práticas astrológicas e a química ainda é alquimia, mas também é o século em que se reflete sobre o método: Descartes, nascido quatro anos antes de Naudé, encontra Gianfrancesco Guidi da Bagno em 1627, o mesmo cardeal para o qual Naudé trabalha entre 1628 e 1641, como secretário e bibliotecário.

Com vinte anos, durante uma série de revoltas e sedições, entre 1619 e 1620, Naudé publica seu primeiro livro de cunho político, o Marphore ou discours contre les libelles), em que o autor defende uma postura de bom senso e garantia da ordem constituída. Três anos depois, Naudé volta a propor uma postura razoável e destacada em seu Instruction à la France sur la verité de l' histoire des frères de la RozeCroix. Trata-se de um texto em que Naudé convida a usar o critério histórico na interpretação de acontecimentos ligados a uma seita esotérica lendária, os irmãos Rosa-Cruz, da qual uma série de manifestos que encheram Paris falava alegando que tal seita estava disposta a compartilhar de seus conhecimentos superiores e misteriosos. Naudé se confronta com tais crenças convidando à razão, traço que o caracteriza em todo seu trabalho, esse de busca de liberdade das falsas crenças. Naudé, nesse mesmo espírito libertário e libertino, em 1625 publica a Apologie pour les grands hommes soupçonnez de Magie, em que nega o sobrenatural quando se apresentam fatos que não conseguimos explicar. Trata-se de uma voz dentro de um debate mais amplo, em que vários autores acusavam os libertinos e ateus de práticas mágicas. Até Homero, Virgílio e outras figuras da antiguidade foram acusados de bruxaria, e nesse clima de irracionalidade, em que, na verdade, os ataques acabavam sendo dirigidos contra os homens mais esclarecidos da época, Naudé toma claramente posição contra a ignorância e a superstição.

Nesse mesmo ano de 1625, Naudé aceita entrar a serviço de Henri II de Mesmes, presidente do parlamento, como bibliotecário. É a ele que, dois anos depois, dedica seu trabalho mais conhecido, o Advis pour dresser une bibliothèque, breve "manual" em que Naudé expõe com clareza a finalidade - que tornará sua própria ao longo da vida inteira - de 
constituir uma biblioteca universal capaz de satisfazer qualquer exigência e necessidade.

Nessa época, Naudé se transfere para Pádua, a fim de cursar medicina, e é nesse ambiente que entra em contato com um conjunto de autores aristotélicos que, em seguida, se ocupa de divulgar na França (KRISTELLER, 1978)

De volta à França, em 1628, passa a serviço do cardeal Bagni e é desses anos a publicação de sua Addition à I'histoire de Louis XI, em que o rei é colocado entre as grandes personalidades renascentistas e apreciado como grande político, além de ter um destaque na cultura, pois o livro impresso foi por ele introduzido na França. No final de 1630, o cardeal Bagni leva Naudé consigo para a Itália, e ele passa a residir em Roma, durante o pontificado de papa Urbano VIII. A cidade papal é, nessa época, a usina artística de Bernini e de Pietro da Cortona, mas é também o lugar em que, em 1633, Galileu foi condenado pela teoria heliocêntrica.

A residência italiana destes anos, como secretário e bibliotecário de Bagni, permitiu a Naudé a frequentação dos ambientes mais cultos da cidade e o contato com a realidade de bibliotecas italianas de vanguarda, como a Ambrosiana de Milão, fundada pelo cardeal Borromeo e inaugurada poucos anos antes, em 1609. Era, essa, uma biblioteca audaciosamente inovadora, tanto na sua concepção arquitetônica, como na composição de seu acervo, que no ato da inauguração consistia em 15.000 obras manuscritas e 30.000 volumes impressos, calculados como sete vezes mais do que os presentes na Biblioteca Vaticana (BOTTASSO, 1984). O fundador desejou uma composição do acervo que compreendesse praticamente todas as obras consideradas cientificamente relevantes, perseguindo $o$ ideal de permitir pesquisas livres e com disponibilidade de informação. Até em relação aos livros colocados no index a escolha foi de torna-los disponíveis na biblioteca, com a única ressalva de mantê-los fisicamente separados dos outros, para garantir o respeito das normas canônicas de acesso mediante autorização das autoridades eclesiásticas.

Não deve ser considerada novidade a prática de admitir livremente o público na biblioteca, práxis já presente nas bibliotecas italianas do século XVI, lembrando que essa face "pública" envolvia os estudiosos capazes de aproveitar os materiais. O conceito de público deve ser pensado nessa dimensão histórica também quando proposto pelo Naudé em seu Advis, para evitar anacronismos. E importante sublinhar a presença dessa biblioteca, conhecida com certeza pela fama e provavelmente de pessoa por Naudé durante sua primeira residência italiana - em 1626/1628 para entendermos em que perspectiva o Advis deve ser colocado e que moldes intelectuais estavam presentes para suas obras de natureza bibliográfica. No Advis, com efeito, encontramos referências explicitas tanto à biblioteca Vaticana como à Ambrosiana, "[...] se não for intenção do senhor igualar a Biblioteca Vaticana ou a Ambrosiana do cardeal Borromeo [...]" (NAUDÉ, 1994, p. 11)

Durante sua segunda residência na Itália, Naudé escreve obras de caráter semi-privado para a família do cardeal, com a exceção de suas 
Considérations politiques sur les Coupes d'Estat (NAUDÉ, 1992), em que Naudé justifica as escolhas da monarquia em relação aos trágicos acontecimentos da noite de São Bartolomeu, chamando em causa, na melhor tradição do maquiavelismo, a razão de estado.

Após a morte do cardeal Bagni, em 1641, Naudé passou a trabalhar para o cardeal Antonio Barberini, com o qual Mazarino, que ainda não era cardeal, já colaborara, de 1632 a 1639, mas logo volta à França, convidado para ser bibliotecário primeiro de Richelieu e, em seguida, para Mazarino.

Acreditamos que as datas, no âmbito da biografia de Naudé, se tornam relevantes, na medida em que permitem apreciar a coincidência das presenças, nos mesmos âmbitos, de personalidades cujos ideais e destino acabam se cruzando, devolvendo-nos uma plenitude histórica que nos permite uma compreensão maior da obra de Naudé.

Nesse sentido, faz-se relevante contextualmente lembrar que o italiano Mazarino, dois anos mais novo que Naudé (nasceu em 1602 em uma cidadezinha do sul da Itália, Pescina), em 1639, quando ainda não é cardeal, mas já é bem conhecido pelas suas habilidades diplomáticas, é convidado a se mudar para a França pelo rei Luis XIII e pelo cardeal Richelieu, que conhecera em 1630, quando suas capacidades diplomáticas impediram o conflito entre Espanha e França.

Quando chega à França já possui uma importante biblioteca, que leva consigo de Roma. Também teve contato com duas das principais bibliotecas, a Vaticana e a Ambrosiana de Milão, que elege a modelo da sua própria. Porém, enquanto Borromeo precisou de oito funcionários para compor o acervo, Mazarino confia os trabalhos a uma única personalidade, Gabriel Naudé, que compartilha com ele a paixão pelos livros. Desde sua chegada em Paris, Mazarino avança rapidamente na carreira, pois em 1641 se torna cardeal e, com a morte de Richelieu, em 1642 se torna ministro. No ano seguinte, quando Luis XIII morre, se torna praticamente o regente de França, pois Luis XIV assume o trono só com cinco anos. Basicamente, Mazarino é, nesse momento, o homem mais poderoso da França, e sua biblioteca consagra seu papel.

Naudé é a pessoa ideal para desempenhar o papel de bibliotecário para ele, tanto pela afinidade na visão política e cultural, como pelas habilidades em comprar muitos livros rapidamente e a baixo preço. Sua estratégia é simples: adquire os livros em blocos, sem selecionar, limitando, assim, os custos e oferecendo ao cardeal quantidades grandes de textos em tempos breves. Graças à sua ampla erudição e a sua rede de relacionamento com os estudiosos e cientistas do tempo, podia contar com os recursos financeiros que Mazarino colocou a sua disposição, tornando, assim, possível a compra de qualquer biblioteca fosse colocada à venda.

O primeiro grande lote de livros foi adquirido comprando, em 1643, a famosa coleção de Jean Descordes, que já interessara Richelieu, e que consistia em um acervo principalmente de história e teologia bem conhecido por Naudé, pois fora ele que redigiu o catálogo. Logo em seguida, adquire 2.000 volumes de história e política francesa de 
propriedade de Ana de Áustria. Nos anos seguintes, Naudé realiza um verdadeiro grand tour pelas cidades italianas e, quando volta à Paris, em 1646, leva consigo 16.000 volumes, que se unem aos 8.000 que, no entanto, o próprio Mazarino adquiriu (KERBAKER, 2015). Enfim, em 1648 a biblioteca somava 40.000 entre livros impressos e manuscritos, para os quais foi encomendada a construção de uma edificação que seguia, em grande parte, as indicações que estavam presentes no Advis, no que diz respeito à estrutura, à orientação das salas, das janelas, das estantes em madeira. No projeto havia até uma porta secundária para o uso dos estudiosos e cientistas com uma inscrição em latim sobre mármore preto na qual todos (que soubessem ler em latim) eram convidados a entrar livremente (PALLIER, 2002).

Tudo isso, porém, já pronto para funcionar, se dissolveu às vésperas da inauguração: eclodiu uma insurreição, obrigando a adiar a abertura, que não aconteceu, pois no ano seguinte um novo parlamento ordenou 0 confisco da biblioteca. Mazarino acabou sendo exilado e a biblioteca leiloada em 1652. Apesar disso, Naudé conseguiu adquirir novamente alguns lotes de livros, que escondeu na abadia de Sainte-Geneviève.

Nesses anos difíceis, Naudé publica o Iugement de totut ce qui a este $i$ prime contre le Cardinal Mazarin, conhecida como Mascurat, escrita em forma de diálogo entre dois impressores, Mascurat e Saint-Ange. Entre os dois se abre uma discussão que toca em assuntos diversos, que abrangem a história, a filosofia, a moral, a política, a religião, as bibliotecas públicas, entre outros.

Quando Mazarino, em 1653, volta ao poder, Naudé, que se encontra trabalhando para a rainha sueca Cristina, resolve voltar para Paris, mas no caminho de volta falece. Desaparece, assim, um dos grandes animadores da estação libertina, em cujo círculo gravitavam figuras como Patin, Gassendi, fabri de Peiresc, os irmãos Dupuy e outros, todos destinados, como Naudé, a serem em boa medida esquecidos, vistos pela crítica como homens voltados ao passado, ainda que eles acreditassem trabalhar para o futuro.

\section{Naudé e as bibliotecas}

Consciente de ser o primeiro a traçar o caminho em um campo ainda ligado ao passado, Naudé, ao redigir o Advis pour dresser uma Bibliothèque, deseja que seu pequeno tratado, ainda que insuficiente e inadequado, possa pelo menos servir de guia. Obra escrita depois de algumas disputas entre os que frequentam a biblioteca do de Mesme, o Advis não é sistemático ou compacto como um trabalho organicamente estruturado, mas reorganiza de maneira sintética as experiências e as discussões do jovem Naudé sobre a prática quotidiana com os livros, com os quais lidava já havia alguns anos. Esse texto se apresenta como uma coletânea de indicações e recomendações práticas, dominadas por um ideal humanista do valor e da importância de uma empreitada como a da realização de uma biblioteca. 
O título esclarece que estamos perante um compêndio e não um verdadeiro tratado, preservando, porém, as características de uma contribuição útil e instrutiva onde, além das anotações mais imediatamente práticas, se encontram algumas afirmações importantes e sintomáticas de uma ampla liberdade de pensamento. São exemplos aquelas no começo da obra contra a escravidão das opiniões comuns, "[...] adquirir conhecimentos de ordem geral no âmbito de todas as artes e de tidas as ciências, em se livrar da servidão e da escravidão de opiniões dadas que nos levam a ditar regras e falar de cada coisa conforme a nossa fantasia" (NAUDÉ, 1994, p.10).

Relevantes nesse tratado são a insistência sobre a utilidade prática de uma biblioteca e sobre a necessidade de seu uso público, ainda que no sentido "restrito" que já apontamos. É somente dentro de um projeto cultural desse tipo que se situam as indicações e as sugestões sobre como organizar e dispor os livros (BARBIER, 2016).

A instância da ordem aparece várias vezes, entre as quais, no último e mais importante capítulo da obra, relativo à finalidade e à utilidade de uma biblioteca. Assim, depois de falar da exigência prioritária de poder desfrutar de bibliotecas abertas ao público que podem ser acessadas pelos estudiosos, Naudé alerta sobre a necessidade de redigir dois catálogos de todos os livros presentes. Um primeiro catálogo temático, em que se delineiam de maneira clara as várias matérias, e um segundo por autores, baseado na ordem alfabética. A organização e a catalogação, elementos imprescindíveis para toda biblioteca, são aqui colocados em sua tarefa de base, ou seja: a capacidade, racional e sintética ao mesmo tempo, de fornecer ao leitor o máximo de informação no menor tempo possível:

[...] a coisa mais necessária seria fazer dois catálogos de todos os livros contidos na biblioteca, em um dos quais os livros seriam dispostos tão exatamente conforme as diversas matérias e disciplinas, para poder ver e saber em um relâmpago todos autores que podem ser encontrados debaixo do primeiro assunto que surgir na mente; no outro, os livros deveriam ser estritamente dispostos e reconduzidos à ordem alfabética de seus autores, tanto para não duplicar as aquisições, como para saber o que falta, e também para satisfazer o pedido de muitos que são, às vezes, desejosos de ler particularmente a obra completa de determinados autores. (NAUDÉ, 1994, p. 109)

Se a organização do material é um elemento relacionado à própria ideia de biblioteca e adquire, portanto, um papel essencial para seu funcionamento, a biblioteca não tem um verdadeiro sentido ou uma identidade se não for universal e pública. A universalidade, com efeito, garante que a biblioteca não seja construída na base de preconceitos ideológicos ou religiosos. Por isso, Naudé não hesita, em vários pontos, em insistir sobre a importância de uma biblioteca não deixar de fora as obras dos hereges. Qualquer censura tornaria de fato uma biblioteca inadequada ao uso público, contrariando o objetivo prioritário que a torna 
universal. Nisso, é evidente a influência da biblioteca Ambrosiana, citada, aliás, várias vezes no texto do Advis.

A utilidade de uma biblioteca consiste em poder ser consultada pelo público; toda biblioteca perde sua razão de existir na falta de leitores e, como observa Naudé, a necessidade de recorrer constantemente às bibliotecas se deve de certa maneira a razões extrínsecas e objetivas quais a brevidade da vida e o grande número de conhecimentos necessários para ser uma pessoa erudita. É possível, no Advis, individualizar um princípio de economia na aprendizagem dos conhecimentos que, ao lado daquele mais explícito da necessidade da ordem e da organização, preside à exigência naudeana de escrever esse texto.

A biblioteca se torna, assim, o lugar privilegiado da memória de um mundo que, sem ela, é destinado a corromper-se e desaparecer. Não é à toa que Naudé, na introdução do Advis, na sua dedicatória ao de Mesme afirma como esta biblioteca ilustrará a memória do presidente, permitindo-Ihe permanecer nas lembranças dos homens.

Para aprofundar a figura do Naudé como bibliotecário, pode ser útil considerar um manuscrito da Bibliothèque Nationale, que contém o catálogo dos livros de Naudé em Paris (BIANCHI, 1993). Trata-se de um documento do qual emergem uma série de indicações sobre as preferências e escolhas do autor.

O catálogo é articulado topograficamente: se considera primeiro as estantes (tablettes) próximas de uma determinada parede, depois os vários móveis e outras prateleiras onde estão os livros. São fichados, assim os vários volumes, examinando para cada um as estantes e fornecendo indicações exatas sobre os lugares em que se encontram os materiais. Cada lista de livros apresenta referências cuidadosas. Não é possível resumir a variedade dos textos colecionados e agrupados por assunto, ainda que sem um visível princípio de coerência interna, aliás com "invasões" frequentes entre disciplinas, como entre medicina e filosofia, filosofia e política, política e moral, moral e história, história e religião, religião e astrologia, só para apontar alguns dos assuntos presentes no catálogo da biblioteca de Naudé. Uma indagação cuidadosa sobre as proximidades entre autores e disciplinas permitiria uma série de leituras cruzadas e enriquecedoras, certamente indicativas de posturas mais compartilhadas e não só de preferências pessoais.

Percorrendo o catálogo, que contém desde a Bíblia a Platão e Aristóteles, de Xenofontes e Plutarco a Quintiliano e Sêneca, de São Tomás aos pais da Igreja, como Tertuliano ou Latâncio, é notável a riqueza em pelo menos três âmbitos disciplinares presentes de forma conspícua e indicativa: o filosófico, o histórico-político e o médico, com autores que recorrem mais vezes, em seções e edições diversas. Platão e Aristóteles, Alexandre de Afrodísia, Cicerone e Sêneca, Tomás de Aquino, Avicena e Averroés, mas também Alberto Magno, Buridão, Pedro de Abano e Lull. Estão presentes os comentadores de Aristóteles, como também muitos filósofos renascentistas como Nicolau Cusano, Ficino, Bovelles e Patrici. Ainda Erasmo e Palingênio Stellato, Montaigne e Charron, Vives e 
Lipsius, bem como Cardanus e Campanella, Bruno e Della Porta, Cesalpino e Fracastoro. Estão presentes Maquiavel, Ramus, Bacon (em várias edições e traduções), Vanini, Gassendi, Basson. Todas essas presenças, aqui só parcialmente indicadas, apontam para os interesses bibliográficos de Naudé, que cobrem o panorama filosófico inteiro com grande atenção para com a filosofia da natureza, tanto na versão "clássica" aristotélica, quanto nas novas impostações dos filósofos do Renascimento, como também nas soluções oferecidos pelos recentes inovadores, como Bacon ou Gassendi. Não podiam faltar, nessa lista, autores pelos quais sempre demonstrou afinidades, como Montaigne, Maquiavel, Cardanus, Campanella, Pomponazzi e Vanini, presentes com várias obras e edições (BIANCHI, 1993).

Há uma presença notável de textos histórico-politicos que se inserem plenamente dentro dos interesses culturais de Naudé, que a esses temas dedicara contribuições específicas, dentre as quais a Bibliographia politica

\section{Ainda sobre Bibliographie politique}

A Bibliographi Politique naudeana é um texto publicado pelo autor em 1633 para o amigo e erudito Jacques Gaffarel, envolvido em compromissos oficiais de caráter político e interessado em ter à disposição um breve volume rico em informações sobre a literatura política. Uma obra, portanto, pensada à luz de uma exigência dúplice: histórico-crítica e didático-enciclopédica. Um texto que, também, podendo ser utilizado com a finalidade de uma consulta rápida, resultava próximo de uma exigência prática de informação. Essa não é a primeira obra de Naudé dedicada ao tema da política, mas é sobre ela que tentaremos nos debruçar.

A Bibliographie é o registro, em um texto contínuo, daquela que Naudé considera a literatura necessária para o estudo da política. Através de títulos e de notas de caráter critico e ilustrativo, o autor forneceu um guia para o estudo desse gênero de literatura. Naudé introduziu o termo "bibliografia" na língua culta com um sentido que, até então, não tinha, o de descrição e indicação de livros. No latim, o termo bibliotheca apontava tanto para a significado de lista de livro quanto para um lugar que hospedava os mesmos (SERRAI; SABBA, 2005).

Naudé, como já apontamos acima, foi um dos maiores representantes do libertinage érudit. Freqüentou o círculo dos irmãos Dupuy e era amigo de Gassendi e Le Mothe Le Vayer. Depois de se tornar conhecido como autor político, primeiro com um panfleto titulado Le Marfore, ou discours contre le libelles, publicou um 1625 uma Apologie pour tous le grands personnages qui ont été faussement soupçonnés de magie, no qual revelava sua descrença em relação à fé, recusando as interpretações sobrenaturais dos acontecimentos que envolveram Paris com os "misteriosos" Manifestos que ofereciam os conhecimentos dos "irmãos Rosa-Cruz" e denunciando às religiões. Racionalista convicto, Naudé aplicava às suas considerações um método antimetafísico, interpretando em termos científicos religião e superstição. Em termos políticos, representa o legado da tradição de Maquiavel, do qual recolhe a visão desencantada das fontes de poder, sempre baseado na força, a 
teoria da separação da política da moral e da religião, e as concepções absolutistas do governo monárquico. Essas ideias se encontram na Addition à l'histoire de Louis XI, de 1630 e, ainda, nas Considérations politiques sur le coups d'état (1639) (GOMEZ, 2000).

No entanto, é a Bibliographie Politique que adquire um destaque europeu, pois através dessa pequena obra Naudé "constrói" as estantes de uma ideal biblioteca universal reservada à política, fornecendo uma ordem não neutral da matéria, mas selecionando, ordenando e organizando os materiais com base nos princípios que norteiam os pensamentos dos libertinos eruditos. A Bibliographie responde à necessidade de um conhecimento filosófico e histórico capaz de guiar a ação do governante. A obra é um pequeno tratado sobre livros de política, em que o autor não dá atenção à morfologia editorial dos textos. Temos, assim, apesar do nome inovador, um exemplo de história literária, tipologia específica de bibliografia (SERRAI; SABBA 2005).

De fato, a Bibliografia, enquanto coletânea de perfis bibliográficos e de livros relativos à determinadas matérias bem como de história das bibliotecas, coincide - no início da Idade Moderna, com a História Literária fundamentada em um cânone enciclopédico de cultura. São, principalmente, as universidades alemãs que desenvolvem, no século XVII, as principais reflexões sobre os fundamentos e as metodologias da História Literária e sobre a construção de sistemas de conhecimento em que inserir a farta produção erudita e literária, aliadas ao amadurecimento de uma mentalidade filológica e à formação de especialidades disciplinares. Resultado disso é que uma das tarefas da bibliografia se torna o de fornecer os instrumentos e o material documentário para a construção teórica das diversas histórias literárias, as quais se propõem o estudo da gênese das ciências na antiguidade e sua disseminação, desenvolvimentos teóricos, métodos, princípios de referência, instituições, centros de elaboração e relações com as outras disciplinas. Com os parâmetros que Bacon colocou à história literária, ela foi entendida como caminho de "progresso" do mundo antigo ao moderno.

Na Bibliographia politica de 1633, Naudé oferece um catálogo de leituras imprescindíveis para o político, com um desenho do que deveria ser a formação de quem atua ao serviço do Estado. Já nas primeiras páginas de sua obra, o autor deixa claros os aspectos fundamentais que antecedem toda formação política:

a)A compreensão, diz Naudé, deve preparar-se para afastar o falso do verdadeiro.

b)O estudioso de política deve estabelecer os critérios extraindo-os dos da filosofia - e confiar nas autoridades que servem de guias para outorgar um sentido e propor uma ordem na confusão do devir histórico.

À luz de outros textos naudeanos, o primeiro ponto constitui um convite a manter o espírito atento às falsificações de alguns historiadores 
ou à aceitação acrítica de muitos tópicos e versões históricas tradicionais; se trataria, basicamente, de um convite a manter uma postura céptica e disposta a aceitar somente versões históricas bem documentadas e intelectualmente bem elaboradas. Só nessa perspectiva o segundo ponto parece em linha com o primeiro, pois Naudé entende que a história pode também constituir-se como relato rigoroso, dos fatos no caso de proceder de um exercício analítico baseado no conhecimento da ciência política e de uma filosofia concreta. Precisamente na Bibliographie politique pretende selecionar uma lista de autores -Tácito, Políbio, Guicciardini...- que, por realizar uma dissecação rigorosa dos fatos e por usar uma metodologia histórica atenta aos elementos que informam o corpo político, constituem uma fonte de inspiração para o governante moderno.

Em uma obra com as ambições da Bibliographie politique não pode faltar, também, um balanço crítico dos autores modernos que trataram adequadamente de filosofia política. Primeiro é Bodin, ao qual seguem Charron, Lipsius e Botero. Como vemos, esta seleção remete ao círculo dos pensadores libertinos da razão de Estado e, pensando principalmente em Bodin, aos que davam impulso a um modelo novo de Estado marcado pela soberania absoluta do príncipe e pela defesa dos interesses nacionais, além das concepções religiosas, de corte universalista o imperial ou de concepções monárquicas solidarias aos interesses particularistas feudais. Por outro lado, destacando a importância do conhecimento dos segredos de Estado para cumprir com as funções próprias do governo, Naudé sinaliza que esse conhecimento ainda é oculto e que os tratados políticos pouco o descortinam.

Ao expor as linhas mestras da doutrina da ação política de Naudé procuramos destacar a sua necessária associação a um modelo de saber que, para ser apropriado, requer uma metodologia e uma minuciosa preparação. De fato, o domínio do uso da força e a aplicação prudente do poder, constituindo o cume da sabedoria política, não são sem dúvida nada mais do que o fruto de um saber mais universal que inclui toda uma doutrina filosófica acerca do mundo e do homem. É fruto, também, de uma crítica textual e histórica aguda e exata que, como já dissemos, é uma instância indispensável para forjar um julgamento fidedigno e uma sugestão política que pode se tornar ação eficaz. A crítica fértil e a erudição requerem, todavia, uma nova organização do saber e uma nova biblioteconomia capaz de oferecer matéria relevante para a formação do juízo. De todo isso Naudé já colocou as fundações no seu Advis.

Para Naudé, receptor da tradição de Pádua, onde estudou, a religião é fábula e construção mítica, ainda que fábula útil e indispensável para o controle político do povo. Em várias passagens o autor revela essa filiação antiteológica e libertina. Percebe-se também, na leitura do texto, ao lado do naturalismo renascentista italiano, a influência do cepticismo, cuja crítica afetava não somente a base das artes liberales, mas também os princípios da religião e da moral.

A biblioteca, quando pretende servir à instrução do homem de ação ou simplesmente dos que aspiram ao conhecimento, deve dar preferência às fontes e às edições em língua original, frente ao predomínio de 
Comentários, Summae e Florilégios que tanto contribuíram a obscurecer o período de domínio da escolástica. Entre as fontes devem ser selecionados aqueles autores e obras verdadeiramente importantes e a esses deve ser dedicada uma atenção especial, diferenciando-os de outros que proporcionam pouco proveito. São essas e outras, acima apontadas, as instruções que, no Advis, convidam a não desapontar os modernos, negando que somente entre os clássicos se prepara o conhecimento, ou a não preferir os grandes volumes sobre os pequenos.

\section{Considerações finais}

A Bibliographie Politique é, assim, um exemplo de História Literária, colocada entre os séculos XVII e XIX no mesmo patamar das outras disciplinas, mas hoje é uma disciplina da qual se perdeu quase completamente até a memória, apesar das centenas de tratados, manuais e programas acadêmicos que dela tratavam. Apesar disso, consideramos que seria necessário um estudo mais aprofundado do papel que ela representou não somente no âmbito da história cultural, mas da bibliografia em seus desenvolvimentos.

Precisa, de fato, considerar que, até o século XVIII, ao lado do florescimento de um novo conceito de ciências, se busca procurar e organizar as fontes que permitem aparelhar uma historiografia como a que autores do porte de Vico e, no nosso caso, do próprio Naudé, produzem e que são, ainda hoje, objeto de discussão para os campos da história e da política.

Como acenamos acima, na base da proposta de uma História Literária encontra-se 0 nome de Bacon, que não somente propõe a realização um repertório neutro de autores e títulos, mas, seguindo nisso a proposta gessneriana, coloca critérios críticos qualitativos, portanto de seleção e juízo científico e cultural.

Na visão de Serrai e Sabba (2005), as funções da História Literária são conceitualmente identificadas com as da bibliografia, e nesse sentido a Bibliografia Política de Naudé representa essa identidade em sua configuração e em suas finalidades, mas faltando uma estruturação autônoma de tipo teórico, acabou se rendendo às formas de organização lógicas e formais que caracterizam a bibliografia propriamente dita, pois ela se configurava como um conjunto de finalidades e orientações elaborado no plano das aplicações e não das elaborações formais.

\section{Referências}

BARBIER, F. La biblioteca di fronte alla prima rivoluzione dei media. Lectio magistralis held by Frederic Barbier on April 21 2016. Disponível em: <http://eprints.rclis.org/30200/>. Acesso em: 21 abr. 2016. 
BIANCHI, L. Per una biblioteca libertina: Gabriel Naudé e Charles Sorel. Em: Canone, E. (org.) Bibliothecae Selectae. Da Cusano a Leopardi. Firenze: Olschki, 1993.

BOTTASSO, E. Storia dela biblioteca in Italia. Milano: Bibliografica, 1984. GOMEZ, C. Saber y poder político en Gabriel Naudé. Res publica, 5, 2000, pp. 111-132. Disponível em: <revistas.um.es/respublica/article/download/26291/25521>. Acesso em: abr. de 2017.

KAMEN, H. O Estadista. Em: VILLARI, R. (Org.). O homem barroco. Lisboa: Editorial Presença, 1995.

KERBAKER, A. Lo scaffale infinito. Milano: TEA, 2015.

KRISTELLER, P.O. "Between the italian Renaissance and the French Enlightenment: Gabriel Naudé as an editor. Renaissance Quarterly, XXXI, 1978.

LAW, J. O Príncipe do Renascimento. Em: GARIN, E. O Homen do Renascimento. Lisboa: Editorial Presença, 1991.

NAUDÉ, G. Advis pour dresser une bibliothèque Bologna: CLUEB, 1994.

NAUDÉ, G. Bibliographia Política. Roma: Bulzoni, 1997.

NAUDÉ, G. Considerazione politiche sui colpi di stato. Milano: Giuffrè, 1992.

PALLIER, D. Les bibliothèques. Paris: PUF, 2002.

SERRAI, A., SABBA, F. Profilo di storia della bibliografia. Milano: Sylvestre Bonnard, 2005. 